DOI: $10.20472 /$ IAC.2018.035.010

\author{
GÁBOR CZIRÁKI \\ University of Sopron Alexandre Lamfalussy Faculty of Economics, Hungary \\ TAMÁS KOVÁCS \\ University of Sopron Alexandre Lamfalussy Faculty of Economics, Hungary
}

\title{
ORDER AND DISTRIBUTION IN PORTFOLIO MANAGEMENT
}

\begin{abstract}
:
This research is an experiment to interpret the nature of portfolios and the best practice of portfolio management. It follows the goal of General System Theory, the transfer of models from other disciplines, which can be used to improve missing mechanisms. An interdisciplinary, self-developed model - M\&M model - is the focus of research, which prescribes the optimal portfolio distribution in the ratio $1: 1: 1: 4$. The model combines the results achieved in the field of organizational development, system theory and chaos theory in one model. This optimization method was compared with the 1:1:1:1 (Modern Portfolio Theory) and 1:1:1:2 (40/20 Portfolio) distributions to search for the optimal distribution of a portfolio. Diversification and focusing are strategic decisions. Using them and managing a portfolio as a system can contribute to deductibles, self-development and sustainability. In a post-crisis period and low global interest rate environment, the demand for simultaneously profitable and crisis-proof investments has increased sharply. To this we would like to carry the self-developed, heuristic M\&M model, as optimization aid and based on it the Rolling Nuts Method, as a continuous value-added process. However, it is important to note that our model is not yet final and is under testing. In the future we intend to analyze more data and research the restructuring as decision-making processes, in order to already compare strategic lifecycle planning.
\end{abstract}

\section{Keywords:}

Investment Strategies, Organizational Development, Portfolio Management, System Theory, Rolling Nuts Model

JEL Classification: C61, G11, 016 


\section{Introduction}

Long-term investment strategies must provide the owner with a constant and relatively stable return. Portfolio management is responsible for the ordering and rearrangement of portfolios. Appropriate decisions should be made in due course with a view to keeping returns and the risk under control. The recent global economic crisis, which is also having an impact today, has shown that even the largest institutional investors suffered heavy losses. The quest for crisis-proof, sustainable and reliable portfolios has grown rigorously. The other aspect of consideration that serves to emphasize and justify the topic is the low interest rate environment, which is attracting investors more and more closely to exchanges where returns can be expected to come. Ever since Nobel laureate Markowitz's Modern Portfolio Theory (MPT), we know that diversification is an important aspect of investment decisions. The power of Diversification has also been put into practice by David F. Swensen, who has proven that even a university - with greater capital levels than some economies - can develop and operate successful investment strategies that can be used to finance one's own organization. Swensen thus demonstrated a kind of self-care (at the institutional level) that worked well for many years, but the crisis hit it so hard that it suffered unexpected and bitter losses. The basic problem is that diversification alone is responsible only for lockout of the risk and not for the exploitation of opportunities. The allocation of investment instruments in different asset classes promises a constant, but not outstanding yield and despite the promised secure alignment does not prove to be crisis-proof. So how do you set up a portfolio to be sure of your investments? Is it possible to expect returns in parallel? Is it possible to take advantage of opportunities and manage risks together? How can you manage portfolios successful? Our research looks for answers to such questions. It is necessary to signal that this study is not the final study of the research, because we still have a lot to do.

The prevailing portfolio theories are based on decades of declarations and the perfect capital market (Markowitz, 1952), or the growing entopic economy (Swensen, 2009) works better than the strategies of other large investors. But even for them, the damage of crisis years was unexpected, although it is known that the economy is moving in cycles (Kondratyev, 1988). The goal of the research could not be other, as the development and presentation of an own, individual, actual strategy, based on interdisciplinary approach and mathematical modeling. The aim of this study is to use a heuristic model to represent the order of the portfolio, to compare the performance of the model and to provide a possible optimization method for decision-making processes. An important aspect of the study is to overlap the previous experiences and models of the investment industry and to present interdisciplinary findings as a recommendable method. 


\section{Theory and methods}

The Rolling Nuts Method ( $\mathrm{RN}^{\mathrm{TM}}$ ) is a portfolio management optimization method that demonstrates the distribution and management of the portfolio elements simultaneously. It was developed on an interdisciplinary basis and has so far only been published on a theoretical level (Cziráki, 2016). Now, this method is presented on a historical horizon in order to demonstrate measurably the comparison of the different investment philosophies.

If you could divide your assets into infinite numbers, unsystematic risk could be eliminated. It proves the power of diversification. But in reality you can't invest in every instrument, so Markowitz, Swensen and many others advise us to divide our assets into 4-5 different asset classes. MPT determines the same proportions of element, the Yale portfolio operates with different distribution. We also know that really wealthy investors swear by focus instead of diversification (Hagstrom, 2001). The Rolling Nuts method tries to show you how to distribute and focus at the same time. According to Cziráki (2016), the basics of this method are briefly the following:

The first approach is Mintzberg's interesting claim in the field of organizational development. He says that you can categorize all organizations in 5 different classes and the important statement of him is that the categories can be determined by a kind of dominance (Mintzbergs, 1979). So every single organization that exists in this world has some dominance. Mintzberg typologizes organizations on the basis of dominance, but the dominance itself is not visible on his figure. (Figure 1).

\section{Figure 1: Mintzberg's 5+2 Model}

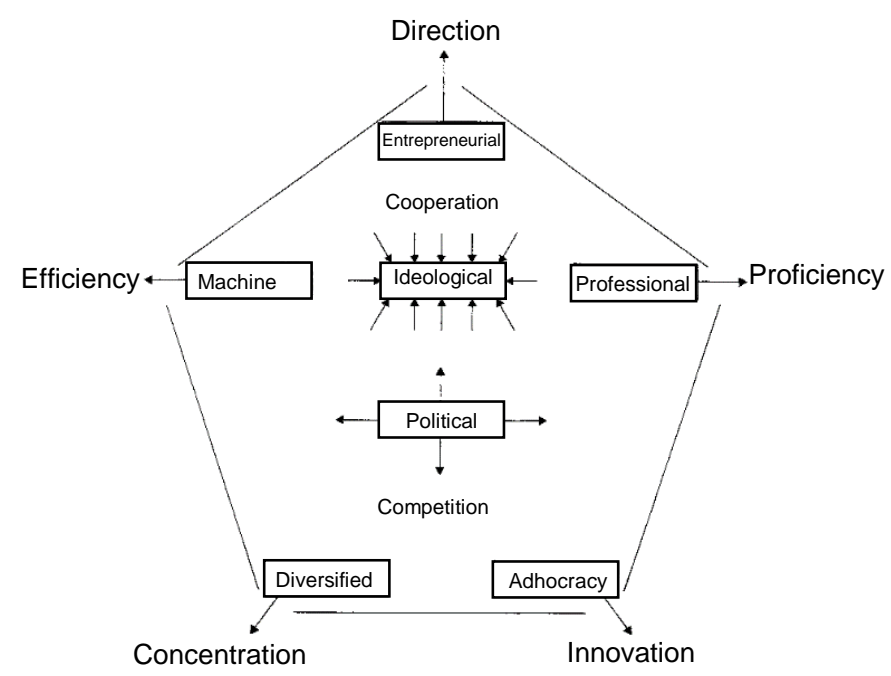

Source: Mintzberg, 1979 
The second approach of the Rolling Nuts method is that it manages a portfolio as a coherent system. According to Ludwig von Bertalanffy's General Systems Theory, an organization is more than just the simple addition of its components. Systems theory suggests that all systems can be divided into global and local parts and the theory describes systems with interacting components (Bertalanffy, 1957). A portfolio can be recognized easily as a kind of organization of money, because the components are distributed and cohesive at the same time. A successful portfolio contains both local and global elements, thus excluding the risks that occur together.

The third and last interdisciplinary approach of the method used is the sensitivity of initial conditions, which assertion comes from the chaos theory, from Benoît Mandelbrot. The Mandelbrot Set is a mathematical formula that models natural growth, but instead of normal geometry, it uses fractal geometry to represent organizations and systems. So he did no less than prove the infinite and give a better picture of the structure of our universe - and thereby all the living, existing organism in it all. Its pioneering effect can still be felt today, the fractal geometry and its application is still a research area. The Mandelbrot Set demonstrates the formula of natural growth, which also has its own limits (see Figure 2).

\section{Figure 2: The Mandelbrot Set in the coordinate system}

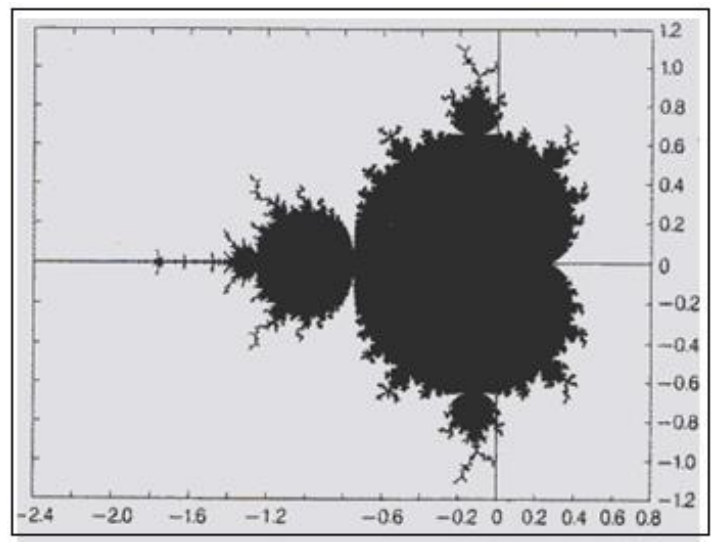

Source: Mandelbrot, 1982

According to the set, our opportunities are infinite, but we have to act between determined frames. Determined and infinite, simultaneous. To use this discovery in portfolio management, we need to recognize the duality of risk and opportunity utilization, which factors also contradict each other. Taking the opposite forces to work in a functioning unit is not witchcraft, it is mimicked by the constituents of our world. According to this theory, a portfolio can be regarded as a unified organization whose natural growth 
and scope can be better described in a more punctual manner. Mandelbrot says that all systems are strictly dependent on initial conditions, so if we know these conditions, we can predict the system's unpredictable future better.

In order to view the Mandelbrot set in a simpler and more comprehensible way, we can draw a pentagon around it and we divide it into 4 similar triangles (Figure 3). This result of the $1: 1: 1: 4$ distribution, which is used by the Rolling Nuts method.

The method builds on the three interdisciplinary principles mentioned above and combines the results of three different scientific fields in a unique way in order to transfer the optimal distribution and management of a portfolio. The model is based on Mandelbrot set and on Mintzberg's pentagon, that's why it is named M\&M Model.

We summarize the above in three points:

1) Representation of dominance which exists in every organization (specifying Mintzberg's model)

2) Determine the optimal distribution of a portfolio according to the geometry of nature (fractal geometry)

\section{Figure 3: The M\&M Modell and its distribution}

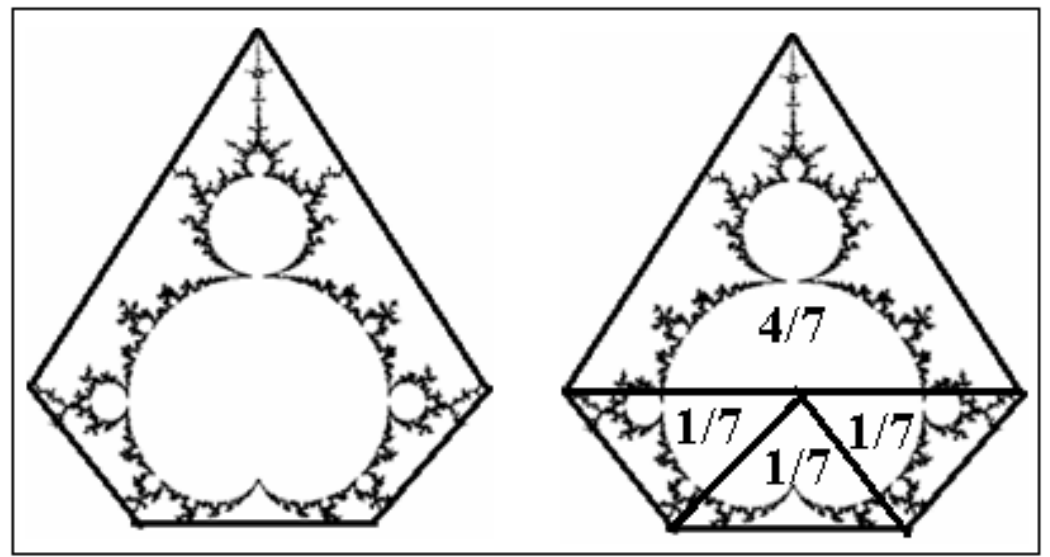

Source: own editing

3) Choosing investment areas according to system theory (global and local elements).

Since a portfolio is a system theory unit, it is very important to take care of the initial conditions because they determine the so-called margin of the system. When designing a new portfolio, one has the opportunity to set up the order of the portfolio. Now we want to 
analyze what happens when portfolio management always keeps in proportion. Therefore, as a first step, we are building a portfolio according to the M\&M Model and we compare it with the evenly distributed MPT portfolio and with a balanced 40/20 portfolio. Last portfolio contains $40 \%$ of bonds and is offered by many investing companies ${ }^{1}$. All portfolios have 4 part, but in different distribution, as you can see on the Figure 4.

\section{Figure 4: The three different distribution policies}

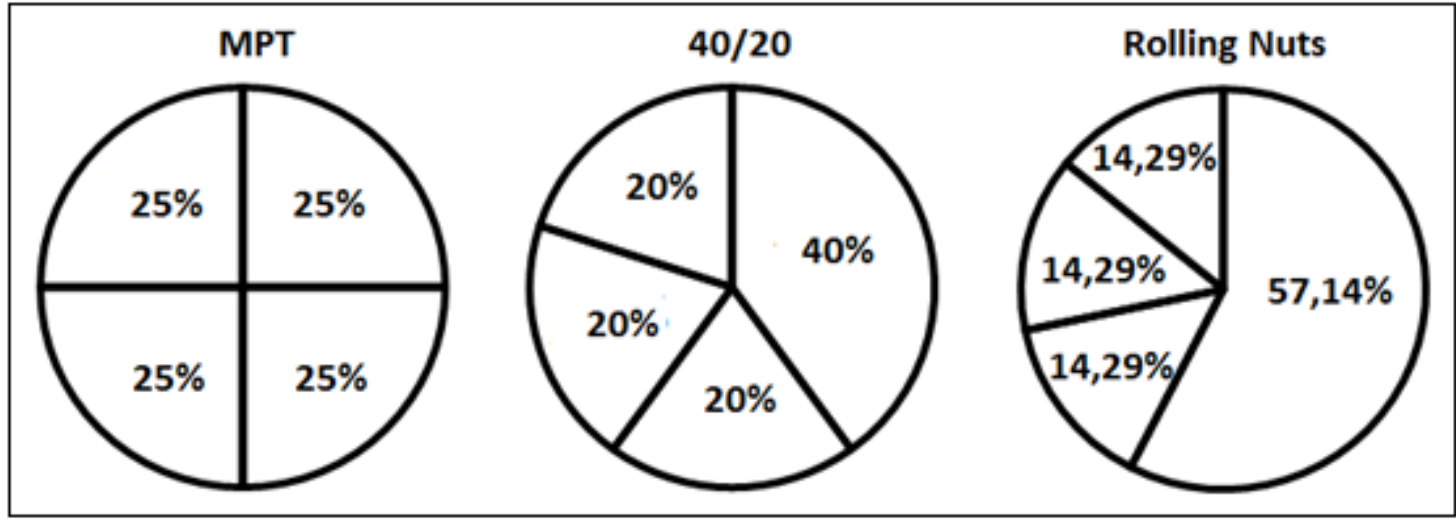

Source: own editing

As a second step, we determine the 4 investment assets that all portfolios have. A sophisticated portfolio includes short, medium and long term components, which we also want to reflect in our study. For example, short-term (within 1 year) returns in a portfolio can be provided worldwide by the foreign exchange market. Since the location of the research is in Hungary, which country is a member of the EU, but not a member of the euro zone, We can take advantage of our own currency. Stock markets, derivatives and alternative assets (e.g. gold) can be responsible for the medium-term returns. Long-term investments may include long-term state-guaranteed government bonds. Based on the above, the following four investment instruments have been determined in our study:

1) EUR / HUF currency pair (short term)

2) DAX Index (medium-term, index-tracker stock fund)

3) Gold (medium-term, alternative investment)

4) Hungarian government bonds (long-term, guaranteed)

\footnotetext{
1 See e.g. Vanguard 60\% Stock/40\% Bond Portfolio, Reeves (2015) or Waggoner (2016).
} 
Since the Rolling Nuts portfolio always has a dominant proportion (4/7), you can adjust the portfolio according to your wishes, preferences or attitude (Appendix $C$ ). In Appendix we show the differently arranged forms of Cziráki's model. According to the four specific investment instruments, four different portfolio could be created, but foreign currency investment practices are far more complex than the assumptions of our model. Therefore, we do not analyze the currency-dominant portfolio. So, you can see in the table: the stock-dominated portfolio (RN ${ }^{\mathrm{TM}}$ (Sto.)), the alternative-investment-dominated one $\left(R N^{\mathrm{TM}}\left(\right.\right.$ Alt.)) and the guaranteed bond-dominated one (RN ${ }^{\mathrm{TM}}$ (Gua.)). We calculated annual returns of a portfolio formed at the beginning of 2005. We took the prices of the first trading day of the year. A very simple and banal example, as if all portfolio positions were closed on the first trading day of the year. With such conditions, we can analyze very precisely the differences between the various distributions.

\section{Results and discussion}

In the Table 1 you can see annual returns of portfolios and the sum and the average of total returns which was realized if the investor renewed his portfolio on every first day of the year by always investing the starting amount of money.

A portfolio value changes constantly, because the stock prices change every day, every hour and the foreign exchange rates change every minute and second. To show differencies of different diversification strategies in our research, we assume a passive management and we do not restructure the portfolios.

Table 1: Annual Returns of MPT, 40/20 and Rolling Nuts Portfolios in \%, 2005-2012

\begin{tabular}{|c|c|c|c|c|c|c|c|c|c|c|}
\hline & 2005 & 2006 & 2007 & $\underline{2008}$ & 2009 & 2010 & 2011 & 2012 & Sum. & i. a. \\
\hline MPT & 14.71 & 12.75 & 15.63 & -6.51 & 15.10 & 13.45 & 4.86 & 7.87 & 77.86 & 9.73 \\
\hline $40 / 20$ & 13.37 & 11.50 & 13.96 & -4.46 & 14.24 & 12.26 & 5.29 & 7.29 & 73.45 & 9.18 \\
\hline $\begin{array}{l}\mathrm{RN}^{\mathrm{TM}} \\
\text { (Sto.) }\end{array}$ & 19.97 & 16.97 & 16.96 & -19.76 & 17.93 & 14.35 & -2.83 & 16.51 & 80.10 & 10.01 \\
\hline $\begin{array}{l}\mathrm{RN}^{\mathrm{TM}} \\
\text { (Alt.) }\end{array}$ & 17.39 & 16.92 & 23.90 & -2.63 & 20.32 & 19.37 & 8.11 & 8.65 & 112.03 & 14.00 \\
\hline $\begin{array}{l}\text { RN'TM } \\
\text { (Gua.) }\end{array}$ & 11.83 & 10.07 & 12.36 & -2.11 & 13.17 & 10.90 & 5.78 & 6.64 & 68.64 & 8.58 \\
\hline $\begin{array}{l}{ }^{\star} \text { Best } \\
\text { Practice }\end{array}$ & & & & & & & & & 123.04 & 15.38 \\
\hline
\end{tabular}

Source: own editing based on data of Appendix 1 and 2 
The return on a portfolio is simply the weighted average of the returns on the individual assets in the portfolio. For example, the return of $\mathrm{RN}^{\mathrm{TM}}$ (Sto.) portfolio in 2005 is calculated using the following equation:

$$
\text { return of } \mathrm{RN}^{\mathrm{TM}} \text { (Sto.) in } 2005=\frac{4}{7} \times 26.99+\frac{1}{7} \times 2.87+\frac{1}{7} \times 20.97+\frac{1}{7} \times 8=19.97
$$

The aim of the study was to find crisis-proof strategies, so the years around the last global economic crisis were analyzed. ${ }^{1}$ The specialist literature mentions 2008 as a crisis year, which can be observed also at the results: in this year all indicated portfolios should book deficit. The best portfolio was the bond-dominated one (RN ${ }^{\mathrm{TM}}$ (Gua.)). Despite the losses, however, average returns were high. Among them the $\mathrm{RN}^{\mathrm{TM}}$ (Alt.) portfolio was the best (14\%). Again, we must emphasize that the procedures presented here are limited to distribution versions without an active trading policy. It is interesting to note that the second-best portfolio was the stock-focused $\mathrm{RN}^{\mathrm{TM}}$ (Sto.) Portfolio. It is the only one that should even book losses twice, but still delivers better results than the MPT or the 40/20 Portfolio. The bond-focused RN portfolio was the worst performing, because the interest rate was down in the period under review.

Diversification plays an important role in satisfying the expectations of the portfolio holder. An active portfolio management or portfolio restructuring can bring even better performance. The question is how.

In the table, the best result of a year is written in bold letters. It is interesting to see that every best result comes from a Rolling Nuts portfolio. If we could restructure in good time, the best practice portfolio management could achive average return of $15.38 \%$.

If we focus on the actual past performance measured with IRR, we find $R N^{T M}$ (Alt.) the best portfolio again with a return of $13.70 \%$ p.a. In this case MPT is the second, and $\mathrm{RN}^{\mathrm{TM}}$ (Sto.) is the third. ${ }^{2}$

\section{Consclusion}

Diversification is a security action, as we have known for decades. Nevertheless, the world's largest investors are severely affected by economic crises. Focusing strategies may be prosperous for investors. RN model is also focusing and based on a special

\footnotetext{
${ }^{1}$ Of course, we will analyze other periods when we continue our research.

${ }^{2} \operatorname{IRR}_{\mathrm{MPT}}=9,49 \%$ and IRR $\operatorname{RN}_{\text {(Sto.) }}=9,12 \%$.
} 
distribution. In this study, RN portfolios seem to be successful. But there are a lot of limitations in this paper so we have to continue analyzes. On the one hand, for example, we need to see other periods and test a lot. On the other hand, we would like to research the opportunity of restructuring. Self-care is an expectation at institutional as well as at private level nowadays. We hope that we will be able to contribute to this in the future.

\section{Appendices}

Appendix A: Prices of EUR/HUF, DAX and Gold on the first trading day of the year (2005-2013)

\begin{tabular}{|c|c|c|c|c|c|c|c|c|c|}
\hline & $\begin{array}{l}2005 . \\
01.03 .\end{array}$ & $\begin{array}{l}2006 \\
01.02\end{array}$ & $\begin{array}{l}2007 . \\
01.02 .\end{array}$ & $\begin{array}{l}2008 . \\
01.02 \\
\end{array}$ & $\begin{array}{l}2009 . \\
01.03\end{array}$ & $\begin{array}{l}2010 . \\
01.04 .\end{array}$ & $\begin{array}{l}2011 . \\
01.03 .\end{array}$ & $\begin{array}{l}2012 . \\
01.02 .\end{array}$ & $\begin{array}{l}2013 . \\
01.02 .\end{array}$ \\
\hline $\mathrm{R}$ & 245.60 & 252.65 & 251.28 & 252.95 & 265.82 & 269.50 & 278.85 & 315.28 & 292.96 \\
\hline $\operatorname{AX}(€)$ & 4260.92 & 5410.24 & 6614.73 & 8045.97 & 4983.99 & 6048.30 & 6989.74 & 6075.52 & 7778.78 \\
\hline $\begin{array}{l}\text { Gold } \\
\text { (USD/ } \\
\text { ounce) }\end{array}$ & 428.70 & 518.60 & 635.20 & 857.00 & 878.80 & 1117.70 & 1422.60 & 1599.70 & 1687.90 \\
\hline
\end{tabular}

Source: own editing; the courses are from finanzen.net, arfolyam.iridium.hu and investing.com

Appendix B: Annual returns of EUR / HUF, DAX, Gold and Hungarian government bonds, in\% (2005-2012)

\begin{tabular}{|l|c|c|c|c|c|c|c|c|}
\hline & $\mathbf{2 0 0 5}$ & $\mathbf{2 0 0 6}$ & $\mathbf{2 0 0 7}$ & $\mathbf{2 0 0 8}$ & $\mathbf{2 0 0 9}$ & $\mathbf{2 0 1 0}$ & $\mathbf{2 0 1 1}$ & $\mathbf{2 0 1 2}$ \\
\hline EUR/HUF* $^{*}$ & 2.87 & -0.54 & 0.66 & 5.08 & 1.38 & 3.46 & 13.06 & -7.07 \\
\hline DAX $^{*}$ & 26.99 & 22.58 & 18.97 & -37.43 & 21.35 & 15.56 & -13.07 & 28.03 \\
\hline Gold $^{*}$ & 20.97 & 22.48 & 34.91 & 2.54 & 27.18 & 27.27 & 12.44 & 5.51 \\
\hline $\begin{array}{l}\text { Government } \\
\text { Bond } \\
\text { Reference } \\
\text { Yield }\end{array}$ & 8 & 6.5 & 8 & 3.75 & 10.5 & 7.5 & 7 & 5 \\
\hline
\end{tabular}

*annual returns

Source: own editing; Bond Reference Yield from akk.hu 


\section{Appendix C: The distributions of 3 Rolling Nuts portfolios used in the analysis}

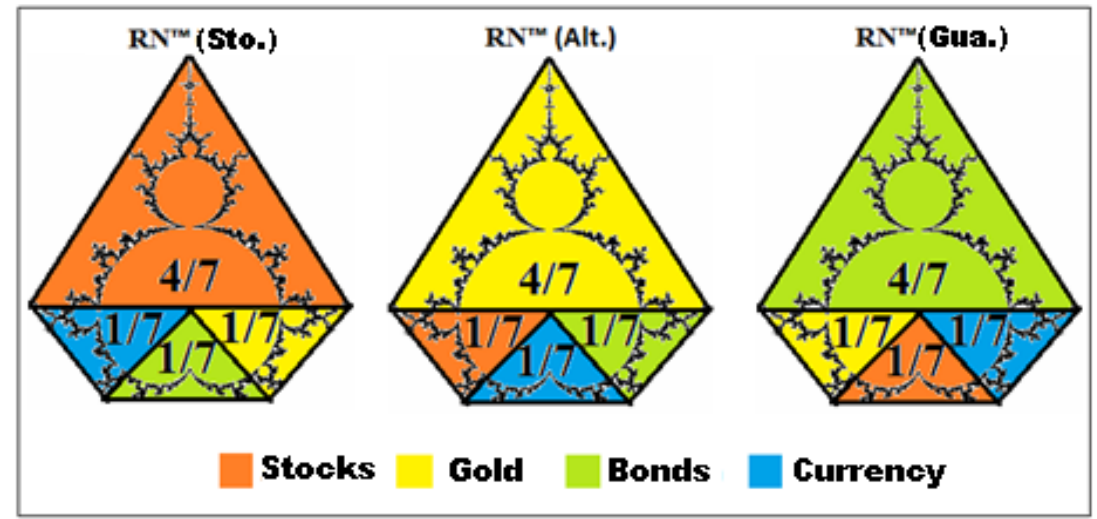

Source: own editing

\section{References}

BERTALANFFY, L. v. (1957). Allgemeine Systemtheorie. Wege zu einer Mathesis universalis. Deutsche Universitätszeitung. 12(5-6), pp. 8-12.

CZIRÁKI G. (2016). Káosz determinált portfolió menedzselés, avagy a 'Rolling Nuts' módszer. In: Kulcsár L., Resperger R. (ed.) Proceedings of 'Europe: Economy and Culture' International Scientific Conference. 1070 p. Sopron: University of Wes Hungary, 2016. pp. 63-78.

HAGSTROM, R. G. (2001). The Warren Buffett Portfolio: Mastering the Power of the Focus Investment Strategy, John Wiley and Sons., 2001.

KONDRATYEV, N. D. (1988). A gazdasági konjunktúra nagy ciklusai. Referátum. Magyar Filozófiai Szemle Nr. 5-6., pp. 559-617., 1988.

MANDELBROT, B. (1982): The Fractal Geometry of Nature. W. H. Freeman and Co., 1982.

MARKOWITZ, H. (1952). Portfolio Selection. Journal of Finance, 7(1), pp. 77-91.

MINTZBERG, H. (1979): The Structuring of Organizations: A Synthesis of the Research. Englewood Cliffs, N.J: Prentice-Hall.

REEVES, J. (2015). The 60/40 stock-and-bond portfolio mix is dead in 2016. Retrived February 20, 2018, from https://www.usatoday.com/story/money/personalfinance/2015/11/09/60-40-stock-bond-portfoliomix-dead-2016/75042316/ 
SWENSEN, D. F. (2009). Pioneering Portfolio Management: An Unconventional Approach to Institutional Investment. Free Press, 2009.

WAGGONER, J. (2016). Why traditional balanced portfolio of $60 \%$ stocks, $40 \%$ bonds can still work for investors. Retrived $\quad$ February $20, \quad 2018$, from http://www.investmentnews.com/article/20160916/FREE/160919950/why-traditional-balancedportfolio-of-60-stocks-40-bonds-can-still

Other websites:

http://www.faz.net/aktuell/finanzen/finanzmarkt/harvard-stiftung-enttaeuscht-anleger-mit-acht-prozentrendite-15207245.html (Retrived January 18, 2018)

http://www.finanzen.net/index/DAX/Historisch (Retrived January 18, 2018)

https://investor.vanguard.com/529-plan/profile/portfolio/4405 (Retrived February 10, 2018)

http://www.arfolyam.iridium.hu/EUR (Retrived January 20, 2018)

http://www.investing.com/commodities/gold-historical-data (Retrived January 20, 2018)

http://www.akk.hu/hu/oldal/statisztika (Retrived January 20, 2018) 